\title{
A New Method of Teaching Spatial Orientation to the Blind
}

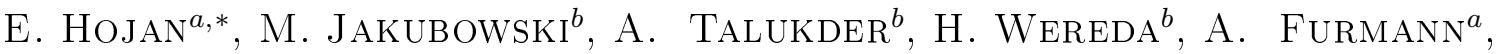 \\ R. Ewertowski ${ }^{a}$, E. Skrodzka ${ }^{a}$, P. Perz ${ }^{a}$, P. Pękala ${ }^{a}$, E. Bogusz ${ }^{a}$, H. Lubawy ${ }^{a}$,

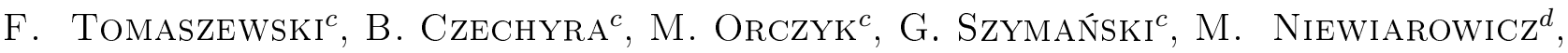 \\ D. HojAn-JEZIERSKA ${ }^{e}$ AND A. JEZIERSKA ${ }^{f}$ \\ ${ }^{a}$ Institute of Acoustics, Adam Mickiewicz University, Umultowska 85, 61-614 Poznań, Poland \\ ${ }^{b}$ Special School and Educational Centre for Blind Children, Przemysława 9, 62-005 Owińska, Poland \\ ${ }^{c}$ Institute of Combustion Engines and Transportation, Division of Rail Vehicles, Poznań University of Technology \\ Piotrowo 3, 60-965 Poznań, Poland \\ ${ }^{d}$ Department of Otolaryngology, Poznań University of Medical Science \\ Przybyszewskiego 49, 60-355 Poznań, Poland \\ ${ }^{e}$ Department of Biophysics, Poznań University of Medical Science, A. Fredry 10, 61-701 Poznań, Poland \\ ${ }^{f}$ Centre of Tourism and Recreation Faculty of Geographical and Geological Science, Adam Mickiewicz University, \\ Dzięgielowa 27, 61-614 Poznań, Poland

\begin{abstract}
Elaboration of a new method of teaching spatial orientation to blind and visually handicapped persons base on urban environment sounds was shown. Task 1 is a questionnaire inquiry on the problems of the blind moving in a big city. In Task 2 a preliminary selection and classification of the acoustic signals and vibrations that can be useful for spatial orientation was made. In Task 3 an analysis of acoustic signals for sound signalisation at pedestrian crossings was made. Some solutions for acoustic signalization were proposed. In Task 4 sounds and vibrations necessary for a library of acoustic events and situations characteristic of a city were recorded. In Task 5 the library was created and arranged to be ready to be used by teachers in the spatial orientation training. The most important outcome of the study was to develop a method of spatial orientation teaching with employment of sounds and verification of the method (Task 6). After verification it is concluded that the method is useful for spatial education of the blind at different levels of their education.
\end{abstract}

PACS: $43.66 . \mathrm{Yw}_{\mathrm{w}}$

\section{Introduction}

Spatial orientation teaching is fundamental for the blind and vision impaired. In Poland such education is provided at special centres for the blind children (10 centres) and in courses organised by the Polish Association for the Blind. The most restricting obstacle for the blind is that of the problems in mobility. The sense of not being able to freely move around can lead to the sense of inadequacy, deterioration of self-esteem, can prevent from all kinds of experiences and knowledge thus gained and lead to total dependency on the guide and others.

Despite much progress in informatics and development of new technologies, the teaching of spatial orientation is still based on old and often ineffective methods. Spatial orientation teaching should employ to a greater degree the sense of hearing which is substantial for the blind. The authors of the project had assumed that it is possible to train the sense of hearing to become an effective tool for spatial orientation to an unprecedented degree $[1,2]$. Analysis of literature on the blind has shown that

\footnotetext{
* corresponding author; e-mail: hojanaku@amu.edu.pl
}

there are no advanced methods for the training of hearing comparable to those proposed for the stimulation of sight. The market offers an increasing number of special electronic tools to assist the blind persons in spatial orientation [3], however, many of them have not been readily accepted as they required much concentration on the signals emitted which were sometimes drowning out vital signals in the environment such as that of the approaching car.

The main aim of the project was to develop a method for spatial orientation training for the blind (children and adolescents) based on the use of sounds produced by the urban environment. The method was developed in close cooperation with the special centre for the blind in Owińska near Poznań. The partners supporting development of this method were Polish Association for the Blind and Society for the Assistance to the Blind and Vision Impaired Graduates form the Centre in Owińska called "To be needed".

\section{Report on results of study performed within the project}

The study preceding development of the method proposed included realisation of six tasks. 


\subsection{Task 1}

The task 1 is questionnaire inquiry on the problems of the blind moving in the urban environment. Questionnaire data were collected in direct interview with respondents. Statistical evaluation of the data permitted determination of directions of further study $[4,5]$.

The most important types of sound assisting in spatial orientation were the following.

- External and internal sounds generated by individual vehicles in different situations, i.e. approaching, accelerating, decelerating, standing with a working engine, sounds of opening or closing door of a vehicle, etc.

- Sounds of traffic, i.e. sounds at the crossroads of different types and size, sounds of single and multilane streets, with or without houses on the sides, sounds at the engineer objects such as a roundabout, viaduct, overpass, tunnel etc.

- City noise without and with moving vehicles

- Specific sounds along the route most often walked by the blind

- Sounds and vibrations generated at characteristic places such as hospitals, health centres, churches, post offices, shops, banks, stadiums, swimming pools, sports halls, parks, fountains, groups of people, children playgrounds, schoolyard, airplanes, cleaning vehicles, construction machines, lawnmowers, bells, flapping banners

- Sounds related to atmospheric phenomena and nature (wind, delicate and strong rain, post-snow mud, dry leaves, rustle of trees and bushes).

\subsection{Task 2}

On the basis of the questionnaire data a preliminary selection and classification of the acoustic signals and vibrations that, according to the blind persons, can be useful for spatial orientation [6-8] was made. On the basis of the same data, the choice of characteristic situations and acoustic events in the city was made for making recordings. Selected sounds and vibrations were recorded in acoustic situations and environmental conditions indicated by the blind respondents. The signals were analysed in the domain of time, frequency, and together in time and frequency (spectrograms), and the temporal-spectral characteristics of the vibro-acoustic signals were made. On the basis of analysis of the sounds recorded by the blind experts the most important sources of sounds in a big city that can be useful for spatial orientation were identified. They were classified according to the degree of complexity and legibility, and according to the situations typical of a city. The analysis has revealed a considerable potential use of vibrations as signals supporting the orientation with respect to the means of transportation and immediate local events. The vibrations sensed in the means of transportation, generated by accelerations or decelerations and changes in the direction of motion can be very informative about the direction of motion, use of brakes, approaching stop etc. Of importance were also the vibrations of the ground (pavement, bus stop) caused by the means of transportation or motor vehicles. Identification and classification of the sources of sound were used for making a database and later a library of acoustic events needed for training in spatial orientation in urban environment.

\subsection{Task 3}

The task 3 is an analysis of acoustic signals in order to establish new standards for sound signalisation at pedestrian crossings. To recognise the level of satisfaction with the currently used acoustic signalisation in Poznań, at first a questionnaire study was made [4]. At the next step, a laboratory study was performed to evaluate the level of annoyance caused by the currently used acoustic signals and their discernibility against a background of street noise. Moreover, the ability to localise the source of sound (sound direction) for different types of acoustic signals and different interfering background noise was investigated. On the basis of the results it was possible to select signals that do not resemble any other known ones that could give false information, are easy to remember, are easily discernible in the street noise, and facilitate localisation of the source of sound, moreover they are not annoying for the inhabitants living near the pedestrian crossings. The acoustic signals selected were tested at an artificial pedestrian crossing and then at a real one by observing the response of the blind persons: time of crossing, speed and route of movement for different types of acoustic signals and different types of interfering noise.

On the basis of the study the following solutions for acoustic signalisation at crossroads were proposed [9].

1. At the crossroads without tram rails the signals proposed are to be periodically repeated complex, of rectangular temporal envelope and filled with rectangular wave of the fundamental frequency $880 \mathrm{~Hz}, 20 \mathrm{~ms}$ duration and $5 \mathrm{~Hz}$ frequency of repetition.

2. At the crossroads with tram rails the signals proposed are to be periodically repeated, complex, of rectangular temporal envelope filled with a rectangular wave of the fundamental frequency $1580 \mathrm{~Hz}$, $20 \mathrm{~ms}$ duration and $5 \mathrm{~Hz}$ frequency of repetition.

3. The level of the acoustic signal should be adjusted to the geometry of the pedestrian crossing and the level of street noise. The adjustment can be realised with the help of a Cross Light SIMulator (CLSIM) program simulating sound field at a pedestrian crossing, written within the project. The program takes into account the type of acoustic signalling and the type of the signal generating device. 
Results of the project are to be implemented in Poznań. After verification of their performance, the application will be made to establish new standards of acoustic signalling at pedestrian crossings in Poland.

\subsection{Task 4}

The task 4 is the method of recording and reproduction of the environmental sounds generated in real acoustic events in the city and vibrations as source of supporting information. This task was realised in a few steps. At first the methodology of multichannel recording of vibroacoustic signals generated in real city was proposed. To meet this challenge a seismic transducer BK 8340 was used to record vibrations, mainly those generated in the means of transportation. For well-defined acoustic situations and events, the sites of recording of the vibroacoustic signals were selected. The recording of vibroacoustic signals was accompanied by image recording by a camera (making film documentation) to unambiguously characterise the site of signal recording and local urban conditions. The acoustic material collected was subjected to analysis of temporal-frequency characteristics in order to determine the conditions and mode of its presentation.

\subsection{Task 5}

The aim of this task was to make a library of acoustic events and situations characteristic of a city life in the form of an acoustic map of the city, CD record and a computer programme for teaching spatial orientation. The choice of the acoustic events and situations was made on the basis of experience of spatial orientation teachers and a questionnaire addressed to the blind persons moving around the city without assistance, members of the Group of Consultants. About 370 of well-defined acoustic events that would help the blind recognize typical situations and sites in the city were collected in the library.

In order to facilitate the use of the library, the acoustic events and situations were divided into six main groups. Each group is characterised by the main subjects, subsubjects, sections and subsections. The systematised acoustic events and situations are arranged into a catalogue comprising 1473 sound files. Each file is accompanied with a text description of the event and suggestions to the teacher as to the teaching tasks and problem solving. The sound files were prepared on the basis of the recordings made within Task 2 and purchased from Sound Ideas. The description was recorded by a blind person with a very good sense of hearing. From among the library files, 520 of them were accompanied with film presentation of the relevant event. The films were addressed to the teachers and persons taking care of the blind. All sound files with text description and films occupy $13.1 \mathrm{~GB}$. The files systematised into directories are recorded on 13 DVD records. The sound library is ready to be used by teachers in the spatial orientation training. To facilitate teachers' work a special instruction for the use of sound files was prepared, a guide book was written and a computer program was developed to enable work at different level of advance [10-12].

\subsection{Task 6}

The most important outcome of the study was to develop a method of spatial orientation teaching with employment of sounds and verification of the method in the Sound Laboratory in Owińska, Communication Map of Poznań, Communication Map of Owińska and the Spatial Orientation Training Park in Owińska. Special tactual relief maps of Poznań and Owińska were prepared coupled with sound effects. The typhlogical maps of Poznan were equipped with sounds using the Pen Friend technology and coupled with binaural records of acoustic events. Thirteen relief figures of typical streets and crossroads were prepared as a linking chain between the maps of typical streets and the actual maps of Poznan. The work within the project also resulted in making a special instruction film addressed to spatial orientation teachers and persons taking care of the blind. The film "The world depicted by sound" illustrates the method by showing the functioning of an adult who has been blind from childhood in the aspect of the sounds received and interpreted by him.

The method was verified at the Sound Laboratory in Owińska, founded within the project. It was also supposed to be verified in the Spatial Orientation Training Park in Owińska, but it proved impossible for formal reasons as the construction of the Park was put off for 2011. Therefore, the practical verification of the method was performed in the city of Poznań. The results were evaluated on the basis of a questionnaire study addressed to 21 blind persons of different education and mobility abilities. The general conclusion from the verification is that the method is useful for spatial education of the blind at different levels of their education $[11,12]$.

\section{Acknowledgments}

The paper reports results of the project entitled "Development of a new method of teaching big city spatial orientation to the blind on the basis of environmental sounds use"; Ministry Decision no. 0393/R/H03/2008/04, registration number: N R11 0008 04, Chief manager Prof. Dr hab. Edward Hojan. The outcome of the project is the method of spatial orientation teaching presented in a book, CD record and DVD film and typhlocartographic sound maps of Poznań and Owińska.

\section{References}

[1] M. Binder, Characters - psychological magazine for everybody 4, (2007) (in Polish).

[2] R. Kowalik, Computer technology for handicapped persons, High School of Computer Science, Gorzów Wlkp. (Poland 2007), (in Polish).

[3] L. Kay, Radio Electron. Eng. 44, 605 (1974).

[4] E. Bogusz, E. Skrodzka, E. Hojan, M. Jakubowski, A. Talukder, D. Hojan-Jezierska, Pol. J. Environm. Stud. 20, 1395 (2011). 
[5] E. Bogusz, A. Furmann, in: Proc. XVI Conf. on Acoustic and Biomedical Engineering, Zakopane, Poland 2009, p. 29 (in Polish).

[6] E. Skrodzka, F. Tomaszewski, B. Czechyra, in: Proc. 20th Int. Congress on Acoustics, Sydney, Australia 2010, p. 283.

[7] E. Skrodzka, B. Czechyra, F. Tomaszewski, Acta Acustica united with Acustica 96, (Supplement 1) 72, (2010).

[8] E. Skrodzka, F. Tomaszewski, B. Czechyra, G. Szymański, M. Orczyk, in: Proc. XVII Conf. on Acoustics and Biomedical Engineering, Zakopane, Poland 2010, p. 131 (in Polish).
[9] A. Furmann, E. Bogusz, P. Perz, H. Lubawy, M. Niewiarowicz, Typhloworld 3, 14 (2010) (in Polish).

[10] A. Talukder, Typhloworld 2, 3 (2008) (in Polish).

[11] A. Talukder, Typhloworld 3, 3 (2009) (in Polish).

[12] E. Hojan, in: Proc. Deutsche Gesellschaft für Audiologie 12. Jahrestagung der Deutschen Gesellschaft für Audiologie, Innsbruck, 2009, p. 111. 